\title{
ALTERACIÓNS CLIMÁTICAS E MUDANZA DEMOCRÁTICA. UNHA APROXIMACIÓN DENDE A ECOLOXÍA POLÍTICA ${ }^{1}$
}

\author{
Alberto José Franco Barrera \\ Universidad de la República, Montevideo \\ bttp://dx.doi.org/10.15304/ag.38.1.4610
}

\section{Resumen}

El cambio climático representa un desafío urgente para las democracias y para las formas de acción colectiva organizadas para luchar contra sus consecuencias. Ante esto, ¿Pueden los sistemas democráticos evolucionar para afrontar estos desafíos? El presente trabajo diseña una reformulación de la democracia liberal basada en dos principios generales: la sustentabilidad y la democratización de la democracia. Teniendo en cuenta que las consecuencias generadas por el cambio climático tendrán un impacto considerable en las formas sociales de organización, analizaré el vínculo entre sustentabilidad y democracia; en primer lugar, para definir de qué voy hablar cuando hable de sustentabilidad. En segundo lugar, para estudiar como los nuevos riesgos originados por el cambio climático exigen una revisión de las formas representativas de democracia.

Palabras clave: democracia, cambio climático, sustentabilidad, teoría política verde.

\begin{abstract}
Climate change represents an urgent challenge for modern democracies and for collective actions forms organized to fight against the consequences of this phenomenon. Can

Recibido: 16/02/2018. Aceptado: 29/05/2018.

${ }^{1}$ Esta investigación conta co apoio do Proxecto Esfera Pública e Suxeitos Emerxentes (FFI2016-75603-R, AIE/FEDR, UE), do Ministerio de Economía e Competitividade. Investigación feita grazas á Agencia Nacional de Investigación e Innovación (ANII) a través das Becas de Posdoctorado Nacional "Fondo Profesor Dr. Roberto Caldeyro Barcia", Convocatoria de 2015, República Oriental do Uruguai.
\end{abstract}


democratic systems evolve to face these challenges? This work designs a reformulation of liberal democracy based on two general principles: sustainability and democratization of democracy. Bearing in mind that the consequences of climate change will have a considerable impact on the social forms of organization, I will analyze the link between sustainability and democracy for two main reasons. In the first place, to settle what I talking about when I talk about sustainability. Second, to study how the new risks caused by climate change will require a new interpretation of the current forms of representative democracy.

Keywords: democracy, climate change, sustainability, green politics, green political theory.

\section{Introdución}

Sen dúbida algunha o medio ambiente e, máis especificamente, o intento de alcanzar unha sociedade sostíbel produciron unha mudanza fundamental na política contemporánea. O devandito cambio de orientación provocou, polo menos, dúas mudanzas importantes. Por unha banda, o feito de que certas teorías políticas comezaran unha análise sistemática dos principios políticos normativos que inspiran aos movementos ecoloxistas, é dicir, cuestións sobre o valor, a racionalidade social ou a participación democrática (cf. Young, 2001). Por outra banda, na área máis substancial, ocorreu unha abordaxe de novas cuestións mentres algunhas máis antigas foron contempladas a partires de ángulos novos e diferentes como, por exemplo, as relacións do ser humano coa natureza e con outros animais, o carácter e os límites da propiedade privada ou os modelos apropiados de desenvolvemento económico (cf. Dobson, 1997; Puleo, 2011).

Noutras palabras, o ecoloxismo foi en gran parte responsábel de introducir as discusións sobre a natureza na teoría política, contribuíndo así ao desenvolvemento do que se deu en chamar o pensamento político verde. Agora ben, esta nova teoría política só pode ser ollada a través da súa relación cun ecoloxismo entendido como unha ideoloxía influínte sobre o discurso político das democracias contemporáneas, a teoría e a práctica dos movementos e partidos verdes, e as políticas públicas medioambientais (cf. Dobson, 1997; Valencia Sáiz, 2000 \& 2004).

En calquera caso, o ecoloxismo político ten hoxe un rol máis relevante como resultado da globalización dos problemas ambientais. É dicir, se até fai pouco os problemas medioambientais e a defensa da sociedade sostíbel eran patrimonio único do ecoloxismo, como movemento político, e, por tanto, constituía un reto á política contemporánea; o novo é que a devandita globalización dos problemas ecolóxicos converteu ao medio ambiente nun problema político tan fundamental que constitúe un eixo vertebrador 
da política no século XXI. Deste xeito, o traballo do pensamento político verde ten a dupla función de identificar o conflito e expresar que a resolución do mesmo depende de cambios estruturais e transformacións políticosociais, cos efectos sobre o comportamento da cidadanía que os devanditos cambios ocasionarán. Non existe exemplo máis claro do anteriormente exposto que a mudanza climática.

Os retos políticos, sociais e ambientais, causados polo cambio climático, están acelerando moi rapidamente a capacidade das actuais formas de democracia para se adaptar. Isto é así porque en torno a este fenómeno xiran múltiples problemas, abordaxes e tópicos de discusión; cada vez máis eventos teñen á mudanza climática como causa ou como agravante: escaseza e aumento dos prezos dos alimentos, aumento da vulnerabilidade nas áreas costeiras, aumentos dos procesos de desertificación; para citar uns poucos (cf. Klein, 2015; Escrivà, 2017; Herring, et.al., 2018).

Agora ben, fóra do interese público e político xerado, que reviviu a importancia do medio ambiente nas axendas políticas, as alteracións climáticas representan unha complexidade epistemolóxica máxima; noutras palabras, condensa o contido que as disciplinas científicas estudan por separado e, ademais, o vencello resultante xera unha nova arquitectura de interrogantes e desafíos para o coñecemento convencional dispoñíbel. Esta nova arquitectura ten a incerteza como compoñente consistente ante a imposibilidade de controlar, e mesmo identificar, todas as variábeis que interveñen e de coñecer como estas se relacionan entre si, especialmente para fins predictivos.

En suma, a democracia podería estar cerca de afrontar tensións en xeitos nunca antes vistos. Con formidábeis desafíos ao virar a esquina, o perigo máis inmediato, e cada vez máis claro, é que a democracia non se vai poder adaptar á loita contra a mudanza climática. Noutras palabras, o fenómeno do cambio climático, xerado polo ser humano, resultado dun proceso de quecemento global causado polo aumento de gases de efecto invernadoiro na atmosfera, pode ser a principal ameaza para o sistema democrático, tal e como o coñecemos. As seguintes liñas exploran por que esa cuestión é de extrema importancia.

Así, nun primeiro momento, se analizará a importancia das alteracións climáticas e as súas consecuencias. Para esta análise utilizarei a sección dedicada aos impactos do devandito fenómeno exposta no Quinto Relatorio de Avaliación publicado polo Panel Intergobernamental sobre Cambio Climático. Nun segundo momento, tratarei o tema do que se entende por sostibilidade neste traballo e, ademais, sinalarei os diferentes xeitos que este concepto posúe á hora de se relacionar coas democracias actualmente exis- 
tente. A intención é subliñar que existen distintos modelos de sostibilidade e que non todos eles necesitan da democracia para ser viábeis. Por último, farei fincapé nos modelos de sostibilidade fortemente vinculados coa democracia coa intención de demostrar que fronte ás alteracións climáticas debemos reformular as nosas opcións persoais, pero tamén as colectivas. De feito, a participación será imprescindíbel para construír políticas públicas que teñan un amplo respaldo social, orientadas cara a descarbonización das nosas sociedades e á adaptación aos novos escenarios derivados das mudanzas que xa son inevitábeis.

\section{A mudanza climática como desafío político do século XXI}

As alteracións climáticas, e máis especificamente o quecemento global, está intimamente vinculadas ao efecto invernadoiro. Isto ocorre polo papel que xoga a atmosfera terrestre (particularmente os chamados gases de efecto invernadoiro que se atopan dentro dela, incluíndo o dióxido de carbono, metano ou o vapor da auga) á hora de manter o calor solar dentro da área delimitada pola devandita atmosfera.

Este efecto invernadoiro aumenta cando as concentracións de gases do mesmo nome na atmosfera aumentan. Estas concentracións, incluíndo aquelas de dióxido de carbono e metano, teñen aumentado como resultado de actividades humanas tales como a queima de combustíbeis fósiles; particularmente dende a primeira revolución industrial. Estes aumentos non tiveron tempo de ser equilibrados a través de varios sumidoiros naturais para o dióxido de carbono, como por exemplo: bosques e outros tipos de vexetación, solos e océanos.

A comunidade internacional estabeleceu un órgano especifico para revisar os últimos avances globais na ciencia climática. O Panel Intergobernamental sobre Cambio Climático ou IPCC é unha colaboración internacional, a maior do seu tipo, criado baixo os auspicios da Organización das Nacións Unidas. Foi fundado en 1988 pola Organización Meteorolóxica Mundial e polo Programa das Nacións Unidas para o Medio Ambiente, e posteriormente apoiado pola Asemblea Xeral das Nacións Unidas. O IPCC serve para revisar e sintetizar sistematicamente o estado actual do coñecemento en relación á mudanza climática, de xeito que representa a mellor referencia do consenso científico. Ese consenso fortaleceuse de forma constante, a medida que a evidencia científica acumulouse; e claro, a medida que o clima quentase, confirmando e permitindo o refinamento de modelos climáticos. 
A revisión global máis recente do IPCC, o Quinto Relatorio de Avaliación, foi publicado en 2014. Antes de discutir moi brevemente o devandito relatorio, abordaremos dúas críticas ben estabelecidas ao IPCC. Primeira, como corpo baseado no consenso, o IPCC é inherentemente conservador. Cada liña do Resumo para Políticos (SPM, nas súas siglas en inglés) de cada novo relatorio debe ser aprobada polos representantes de todos os países participantes. Iso serve para evitar controversias, pero tamén elimina visións discordantes e, ademais, debido aos prazos de submisión de artigos ao longo do proceso de revisión, exclúe as investigacións máis recentes. En segundo lugar, o IPCC está limitado por mandato a ser relevante para as políticas, pero sen prescribir política algunha. É dicir, isto presupón a obriga de ser apolítico, aínda cando a ciencia publicada indique sen dúbida ningunha que continuar como até agora é incompatíbel cos obxectivos declarados na loita contra a mudanza climática. En calquera caso, as críticas xerais non deben facermos esquecer que os relatorios do IPCC son os traballos máis importantes na literatura sobre alteracións climáticas xa que sintetizan unha inmensa cantidade de investigacións publicadas.

O Quinto Relatorio resume ás malas noticias sobre os impactos da mudanza climática en cinco puntos chave: 1. Ameaza a sistemas únicos (en particular o xeo do Ártico e os arrecifes de coral); 2. Eventos climáticos extremos (ondas de calor, precipitacións extremas e inundacións nas áreas costeiras). 3. Distribución do impacto (en particular no referido á produción agrícola e ao desenvolvemento desigual). 4. Efectos engadidos dos impactos globais (impactos na economía e na biodiversidade de múltiples tendencias combinadas); e, 5. Eventos en grande escala (impactos específicos asociados ao cruzamento irreversíbel de puntos de inflexión, como a perda de xeo continental e o conseguinte aumento do nivel do mar).

Noutras palabras, a mudanza climática terá grandes impactos; por exemplo, na saúde, como resultado de eventos climáticos extremos cada vez máis frecuentes, teremos cambios na incidencia e diseminación de enfermidades infecciosas e efectos na saúde mental ao aumentar a exclusión social; por mencionar só dous. Ademais, xa está a ter repercusións sociais máis amplas non menos importantes dado o aumento do nivel do mar que xera impactos nos asentamentos humanos nas áreas costeiras; a medida que as modificacións na produtividade e nas prácticas agrícolas están forzando a máis migracións; e, tamén, como estes feitos producidos ou aumentos pola mudanza climática comezan a xerar cambios ou choques na economía global.

Por outra banda, non podemos esquecer que o Quinto Relatorio tamén incide en que as alteracións climáticas afectarán de xeito desproporcionado 
a aqueles que xa viven na pobreza ou en situacións de marxinación. Engade, ademais, que o agravamento das condicións xa existentes de desigualdade ocorrerá non só entre países, senón dentro dos países (cf. Sekulova \& van der Bergh, 2013; Chancel \& Piketty, 2015).

Non parece existir, entón, ningún campo da actividade humana que sexa inmune ao impacto das alteracións climáticas. As consecuencias deste fenómeno, e das políticas públicas que son, e serán, tomadas para retardalo ou reducilo, implicarán un cambio na matriz tecnolóxica das nosas sociedades e nas condicións de vida da gran maioría. A democracia debe ser capaz de afrontar estes desafíos, pero antes de abordar esta cuestión é necesario falar da teoría política verde e de sostibilidade.

\section{Democracia e modelos de sostibilidade}

A teoría política verde abarca unha diversidade de principios éticos e políticos, de escolas e teóricos que tratan sobre as dimensións preceptivas de dous amplos obxectos de estudo: Primeiro, a relación entre os seres humanos e a natureza; e, segundo, a relación entre a sociedade e o mundo natural. Dende esta perspectiva, a achega máis orixinal da disciplina dentro da teoría política radica en tres aspectos (cf. Arias Maldonado, 2008). Primeiro, a introdución das relacións socio-ambientais como tema propio e central da análise política normativa. Segundo, o mantemento dunha serie de criterios sobres os cales fundamentar unha crítica á orde social existente e estabelecer algúns dos principios da sociedade boa e, en consecuencia, suxerir ideas para transformar un presente insostíbel nunha sociedade sostíbel; e, terceiro, a ampliación do horizonte da análise política preceptiva cara a outros elementos, tales como: o mundo natural non humano, os animais non humanos ou as vindeiras xeracións. É dicir, crea unha relación, non coñecido até agora, entre a dimensión ambiental e os discursos políticos sobre a xustiza distributiva.

A súa tarefa, en definitiva, é estabelecer unha reflexión normativa sobre a adaptación social necesaria do noso modelo de sociedade cara a unha sociedade sostíbel. Agora ben, a sostibilidade tamén ten que ser concibida tanto como un principio normativo, porque define as condicións de supervivencia e perpetuación da especie humana dentro da natureza; como un principio que esixe un proceso de toma de decisións para definir os seus modelos.

Pero, que é a sostibilidade? De xeito xeral, a sostibilidade pode ser definida como o ordenamento das relacións do ser humano co seu ambiente, 
isto é, a obtención do equilibrio entre o social e o natural. É unha sostibilidade perseguida en vez de conseguida espontaneamente; implica, por tanto, unha sociedade que organiza reflexivamente a súa relación co medio ambiente. É un principio neutro, porque non di ren sobre o carácter dese equilibrio, nin da forma desa organización; noutras palabras, un obxectivo xeral é formulado e necesita dunha definición adicional.

Sen embargo, esa natureza xenérica da sostibilidade ten os seus límites, unha vez que, inda que amplamente formulada calquera forma de sostibilidade ten un contido mínimo fóra da súa decantación normativa. Ese mínimo non é senón a garantía da viabilidade ecolóxica dos sistemas naturais nos cales se sustenta o sistema. Con todo, a garantía de tales mínimos non di ren sobre o grao de protección que será dispensado ao mundo natural ou os medios que serán utilizados para alcanzar o equilibrio socioambiental, nin específica a forma da súa articulación política. Todo iso permanece aberto, indefinido, inacabado. Agora ben, estas cuestións teñen unha resposta técnica pero é necesario respondelas politicamente primeiro. Así, a sostibilidade é, por riba de todo, un principio normativo, cuxa definición debe ser aberta a unha decisión pública. Sempre é necesario preguntar que debe ser sostido, por canto tempo e por que razóns (Franco Barrera, 2013:126).

Dado o seu carácter xenérico, o contido específico da sostibilidade dependerá da disputa entre as diferentes nocións da mesma. Inda así, estabelecer unha tipoloxía das diferentes variábeis de sostibilidade non é unha tarefa simple, especialmente considerando a complexidade dun debate onde a ciencia e a economía, a política e a moral, e a prospectiva e a historia se confunden. A clasificación característica é aquela que enfronta un modelo forte de sostibilidade, que responde as aspiracións de certo ecoloxismo, con un desenvolvemento sostíbel entendido como a resposta do sistema á ameaza que a sostibilidade forte representa. Este esquema, con todo, é insuficiente. É máis útil deseñar un contínuum, que teña nos seus estremos as chamadas sostibilidades forte e débil e onde sexa posíbel acomodar as diferentes formas que o principio pode adoptar (cf. Arias Maldonado, 2008).

A vantaxe dunha diferenciación entre concepcións forte e débil da sostibilidade é que a mesma permita discutir a cuestión da substituibilidade do capital natural. De feito, en todas as distincións entre sostibilidade forte e débil, a devandita substituibilidade, a súa posibilidade e o grao en que é convínte ou desexábel, xorde como pregunta central que polas súas propias implicacións expresa a posición adoptada sobre outras variábeis, como a xustificación ofrecida para a aplicación do principio ou a prioridade estabelecida entre necesidades e intereses humanos con aqueles non humanos. 
Noutras palabras, a distinción entre sostibilidade forte e débil responde a unha interpretación da mesma organizada principalmente en torno dun criterio concreto. Este criterio é aquel da posibilidade de substituír o capital natural polo capital humano (cf. Holland, 1998).

Non obstante, as tipoloxías que describen as diferentes formas que a sostibilidade pode adoptar non posúen unha dimensión política que permita esclarecer as relacións existentes entre ese principio e a súa posíbel articulación democrática. Por esta razón é necesario distinguir entre dous modelos de sostibilidade, considerando a relación entre sostibilidade e organización social; unha primeira, coñecida polo nome de sostibilidade normativa ou aberta, forte ou necesariamente vinculada á democracia; e, a chamada sostibilidade tecnocrática ou pechada, débil ou continxente con relación á democracia (cf. Arias Maldonado, 2008).

Esta última é aquela na cal o contido da sostibilidade, isto é, o deseño das relacións económicas, sociais, políticas e culturais co medio ambiente é mediado cientificamente ou ideoloxicamente, respondendo a cálculos e avaliacións técnicas ou a un núcleo de principios que formarían un modelo pechado sen ningunha discusión pública. Esta forma subliña a viabilidade técnica do modelo, ou a súa coherencia ideolóxica, fronte a súa discusión democrática. A sostibilidade tecnocrática ou fechada ten dúas variantes; por unha banda, o modelo liberal-tecnocrático, onde a sostibilidade é concibida en termos científicos, técnicos e administrativos en vez de en termos políticos. O modelo socioeconómico en si mesmo é capaz de resolver os problemas ambientais que, en ningún caso, cuestionan o devandito modelo.

Por outra banda, o modelo eco-utópico, onde a construción ideolóxica sobre o tipo correcto de sociedade, e incluso da persoa correspondente ao mesmo (cooperativa, desinteresada, amante da natureza) está fóra de calquera discusión pública. Tamén aquí os medios para conseguir a sostibilidade son dados e sen posibilidade algunha de modificación. A completa construción social, de feito, está subordinada ao respecto dos límites ecolóxicos.

Pola súa contra, a sostibilidade normativa ou aberta considera a sostibilidade un valor cuxa realización é necesaria pero non explícita as condicións para iso. A política é emancipada das disciplinas técnicas e o contido da sostibilidade está aberto ao diálogo e á deliberación social. Non se trata de excluír o coñecemento técnico, necesario dende todos os puntos de vista para alcanzar a sostibilidade, senón de subordinalo á política. A técnica ten unha xerarquía de valor que o imperativo científico non pode roubar do diálogo público, entre outras cousas porque a sostibilidade non é soamente unha noción ecolóxica; tamén é unha decisión sobre como queremos 
vivir. Con todo, a crítica da ciencia que subliña o seu status como un filtro cultural e o seu carácter como ferramenta de lexitimidade a través da neutralidade, non podo levar ao descrédito do papel dos especialistas e técnicos cuxo concurso permanece indispensábel. O que se debe intentar, por contra, é equilibrar o seu desempeño, vinculalo aos controis democráticos e ao discurso público (cf. Swyngedouw, 2010 \& 2011); alén diso, dada a ausencia dun monopolio da verdade obxectiva, os mecanismos necesarios para facilitar a resposta e o contraste entre diferentes visións técnicas deben ser artellados. Deste xeito, a pluralidade de posíbeis formas de sostibilidade, así como a pluralidade de intereses e as versións de vida subxacentes, serán plenamente recoñecidas.

A concepción aberta da sostibilidade estabelece, entón, unha relación forte ou necesaria coa democracia, unha vez que a definición do principio esixe, pola súa propia natureza, a deliberación e decisión pública. É dicir, é a cidadanía a través dos diferentes procesos e mecanismos participativos quen é chamada a decidir cal é a forma preferida de sostibilidade, así como a vixiar e controlar a súa redefinición e adaptación constantes á luz da súa aplicación e desenvolvemento. A sostibilidade, por tanto, non é concibida como un estado regular e constante senón como un proceso dinámico e en adaptación e mudanza permanentes, axustado ao propio carácter das relacións socio-ambientais. Esta condición do proceso facilita a apertura permanente do principio e a súa redefinición e control democráticos.

Noutras palabras, a condición preceptiva vencella necesariamente a sostibilidade e a democracia, xa que o contido da primeira só pode ser definido e aplicado a través desta última. Dada a súa natureza aberta e reflexiva, a construción pública e discursiva do principio da sostibilidade atopa na democracia o mellor medio de realización. En ningún caso, sen embargo, iso garante que a sostibilidade sexa adoptada como un principio público e como un obxectivo xeral.

Non obstante, a sostibilidade, en calquera das súas manifestacións, representa desafíos para a democracia. Un primeiro reto é o pensamento a longo prazo para un desenvolvemento xenuinamente sostíbel fronte a crises de curto prazo e ciclos electorais. Iso, ao tempo, pódese asociar a síntomas máis xerais de malestar na democracia en moitos países; exemplificados pola apatía do corpo electoral, a falla de confianza nos políticos e os obstáculos do mundo real para conseguir unha participación verdadeiramente inclusiva. Un segundo reto constitúen os intereses non representados, particularmente os intereses daqueles sen dereito ao voto (incluíndo á propia natureza, ás persoas non humanas, a infancia e as vindeiras xeracións) e 
daqueles outros que non posúen unha voz efectiva. Un terceiro reto é a dificultade de facer escollas lexítimas e responsábeis sobre os 'trade-offs' cando é difícil ver solucións de 'win-win-win' que funcionen para a economía, o medio ambiente e para a sociedade ao mesmo tempo.

En definitiva, a sostibilidade precisa da democracia á vez que a democracia necesita da sostibilidade. Con todo, dado que esta garantía non pode ser obtida, a teoría política verde debe ser o elo necesario entre a sostibilidade e a democratización da democracia. Un modelo de democracia verde terá que atopar un xeito de conxugalos.

\section{Formulando unha democracia inclusiva e verde}

A existencia de dous obxectivos cuxo vencello é posíbel, pero que poden ser entendidos de forma independente, dada a variedade de concepcións e desenvolvementos que cada un admite, corre o perigo de desnaturalizar unha futura democracia verde. É dicir, podería ocorrer o desenvolvemento dun modelo en que todos os obxectivos de democratización foran alcanzados, pero onde a expansión dos principios e institucións democráticos non tiveran relación co principio de sostibilidade. Sen embargo, podería ser que a implementación e a manutención da sostibilidade non sexan acompañadas dunha mellora democrática; basta ter en mente as formas tecnocráticas ou fechadas de sostibilidade mencionadas máis enriba. Por iso, na ausencia dunha diferenciación similar nunha literatura onde os dous termos son usados indistintamente, é necesario distinguir entre democracia ecolóxica e democracia verde.

A democracia ecolóxica designa ese modelo de democracia orientado exclusivamente na dirección da sostibilidade, isto é, reestrutura a forma de asegurar o equilibrio da sociedade cos sistemas naturais dos cales depende alén de calquera modificación nas bases do funcionamento institucional da democracia. A democracia verde, non obstante, refírese ao modelo preceptivo que integra a sostibilidade e a democratización da democracia de forma necesaria, é dicir, estabelece un vencello de principio entre a política democrática e a política da sostibilidade. A xustificación da forma democrática escollida non se debe basear só na proposta de democratización, senón tamén e ante todo, na adecuación en relación ao principio de sostibilidade, entendido como sostibilidade aberta.

A crítica da democracia liberal e a sinalización dos seus límites desempeñan un papel importante no perfil institucional do modelo democrático 
verde baseado nun vencello necesario entre unha concepción normativa da sostibilidade e a forma inclusiva de democracia ${ }^{2}$. Nas seguintes liñas, presentarei diferentes argumentos na defensa deste modelo pero é necesario lembrar que a nova condición da democracia resultante non impide a preservación dos aspectos da democracia liberal que sexan beneficios para a súa articulación e funcionamento, nin impiden a crítica e a adaptación dos modelos deliberativos e directos de democracia, cuxa corrección serve de acordo co estabelecemento dun modelo inclusivo e verde de democracia.

Os valores verdes xurdirán máis facilmente nun marco de deliberacións. A natureza aberta do procedemento inclusivo, cuxo tenor argumental e racional permite a exposición ordenada e persuasiva de todos os valores e intereses, eliminará as distorsións do proceso político liberal e permitirá o xurdimento de valores ecolóxicos, dada a súa razón obxectiva. Neste sentido, as opcións que preservan a integridade ecolóxica están localizadas nunha posición forte na situación ideal da fala porque o feito de que a vida humana dependa de tal integridade transfórmaa nun interese xeneralizábel obvio (cf. Dryzek, 1990; 1994; 2006). Na verdade, este é un interese que, unha vez admitido, terá que ser obxecto de discusión, e nada garante que, a pesares da súa condición de interese xeneralizábel, sexa efectivamente adoptado, menos aínda que de orixe a un proceso de definición e aplicación do principio de sostibilidade. Esta limitación insuperábel afecta a todos os valores verdes dentro da estrutura inclusiva; a validación que a ecoloxía lles dá non é diferente da validación que outros lles atribúen ás súas respectivas concepcións sobre o ben. Non existe garantía de que os valores ecolóxicos sexan aceptados como produto de conversas libres e iguais (cf. Dobson, 1993). É verdade, sen embargo, que a propia natureza da deliberación aumenta as oportunidades de que eses valores sexan considerados e pesados racionalmente; a democracia inclusiva é, en principio, un marco máis favorábel có liberal para a súa aceptación social.

O procedemento de deliberación é adaptado á natureza pública dos bens ambientais. O carácter público único dos bens cuxa protección se pretende é aquilo que permite defender a adecuación da democracia inclusiva como procedemento de decisión sobre os mesmos. Non hai que esquecer que esa forma de toma de decisións non revela valores xa existentes, senón que os

${ }^{2}$ Neste traballo entendo por democracia inclusiva as investigacións sobre o tema do profesor Ramón Maiz (2006) e non aquelas do profesor Takis Fotopoulos (1997). A escolla pola primeira opción está determinada pola síntese, moito máis conciliadora, que se realiza cos outros modelos de democracia. 
constrúe activamente. As persoas non teñen un determinado conxunto de preferencias; as actitudes que xorden depende da institución que moldea esa articulación, non existe institucións neutras. A formación de actitudes en relación aos bens públicos envolve un tipo de proceso diferente daquel da formación de preferencias sobre bens privados; é esencialmente unha actividade pública.

Paréntese primeiro: o problema das preferencias. O modelo de deliberación transcende a mera agregación de preferencias, propia do modelo liberal, para fomentar a súa discusión e transformación durante a deliberación, pero esta é unha presunción que causa algúns problemas. A defensa da deliberación democrática debe prestar atención aos coñecementos actuais sobre raciocinio práctico e motivación política (cf. Przeworski, 2010); non é razoábel esperar que a cidadanía transforme masivamente a súas preferencias durante a deliberación (cf. Johnson, 2001; Mouffe, 2012). Por tanto, a cidadanía debe abrir as súas preferencias cara a un proceso de comparación, discusión e, se procede despois dunha avaliación racional, transformación; con todo non é seguro que iso ocorra. A posibilidade de que o conflito público de preferencias subxectivas reprodúzase no proceso de deliberación do marco inclusivo non pode ser desbotada, comprometendo os resultados consensuais. Inda que isto en si mesmo non sexa un problema, na medida en que a necesidade de non estender o debate alén do razoábel e a necesidade de chegar a acordos esixen o estabelecemento do voto no proceso de deliberación, si resulta máis problemática a posíbel resistencia da cidadanía a unha exposición real das súas preferencias ao debate e á interacción.

A democracia inclusiva permite incorporar ao proceso democrático axentes e voces tradicionalmente excluídos do mesmo. A igualdade que preside o procedemento de deliberación significa que todas as voces aproveitan a oportunidade de ser escoitadas durante o curso do mesmo, de xeito que as perspectivas e abordaxes presentes no devandito procedemento podan ser multiplicadas, dando espazo a axentes e intereses subestimados ou subrepresentados no proceso político liberal. A democracia inclusiva promove un pensamento ampliado que pode traer ao debate os intereses do mundo natural, na medida en que se refire "á representación imaxinativa, para nós mesmos, das perspectivas e situacións doutros durante a formulación, defensa ou discusión das regras colectivas propostas" (Eckersley, 2000:121). As consideracións morais do mundo natural derivan non da competencia lingüística, senón da súa capacidade de autoxestión, de xeito que a súa incapacidade de comunicación debe ser complementada por axentes huma- 
nos que asumen os intereses da natureza como propios; a democracia inclusiva non só permite a representación indirecta de axentes subrepresentados, senón que insiste na mesma (cf. Eckersley, 2000; Whitworth, 2001). Canto maior o número de persoas que decidan intervir no debate, maior será a posibilidade de que algúns deles asuman os intereses da natureza; e, así, a democracia inclusiva pode crear unha situación onde os intereses alleos a un mesmo sexan escoitados como propios e, por conseguinte, tomados en consideración (Goodin, 1996:847). A limitación do argumento é de volta a incerteza do debate e a imposibilidade de garantir calquera tipo de resultado; escoitar non é dar peso, e a inclusión de intereses e voces anteriormente excluídos do proceso político non implica a aceptación automática, inda que o contexto político e social sexa, obviamente, máis favorábel.

A democracia inclusiva permite, pola súa natureza, estender a comunidade política e incluír na mesma ao mundo natural. Dado o carácter indefinido dos límites da comunidade política, unha política de deliberación permite desmantelar aquilo que a separa o mundo do natural, unha vez que a democracia inclusiva "encaixa máis facilmente con límites indefinidos, porosos, discutidos e problemáticos" (Dryzek, 1996:146). O proceso de deliberación non sería afectado polas limitacións dun discurso público convencional que soe excluír todo o que non pode ser indicado de forma clara e explícita, nin sostido de forma recoñecíbel (cf. Torgerson, 1999). O recoñecemento de capacidade á natureza garante o respecto polos recursos naturais e os procesos ecolóxicos, pero para iso é necesario tratar os múltiplos sinais naturais co mesmo respecto que lle damos aos de orixe humana (cf. Dryzek, 1995). Sen embargo, limitar a representación aos animais nonhumanos é convínte se pretendemos ser máis eficaces, porque canto maior é a gama de representación, peor serán os resultados en termos de respecto polos valores ecolóxicos (cf. Dobson, 1996). Dito isto, e tendo en consideración que as relacións entre seres humanos e animais son inevitábeis, será necesario conceder dereitos políticos a estes últimos con base ao tipo de relación que manteñan coa sociedade humana (cf. Donaldson \& Kymlicka, 2011). Con todo, o sistema social non se pode comunicar co sistema natural; só é posíbel a comunicación dentro do sistema social sobre ese outro sistema. A democracia, como práctica discursiva, é inevitabelmente humana (Weale, 1993:342).

Paréntese segundo: deliberación, exclusión, decisión. A democracia deliberativa, na súa propia base, contén unha forte exclusión potencial debido á natureza da práctica que constitúe o seu centro, isto é, a deliberación. Asumir que todos os cidadáns e cidadás son libres no momento da delibe- 
ración pública para tomar decisións colectivas máis lexítimas e racionais é ignorar que a deliberación é en si mesma unha práctica exclusiva. Deliberar é construír argumentos e defendelos a través da fala, persuadir da súa bondade por medio da retórica, entender axeitadamente os argumentos dos outros e xulgalos á luz dos propios e da defensa que dos mesmos se formula. Non é, claro, nin conversa nin fala, senón outra cousa. Do mesmo xeito, as regras da deliberación non son neutras, porque o discurso asertivo e de confrontación é máis valorizado có discurso tentativo, exploratorio ou conciliador; o que revela finalmente como o principio da superioridade do mellor argumento reintroduce o poder no debate democrático, dando orixe a unha visión agonística da esfera pública, noutras palabras, a deliberación é competición. Como consecuencia deste nesgo competitivo e daquela inclinación racionalista, a deliberación adopta un carácter elitista e excluínte daqueles individuos ou grupos con menos capacidade de desenvolvemento dun tipo específico de discurso ou cuxas formas de comprensión e expresión non encaixan coas formas privilexiadas no proceso de deliberación.

Unha vez que os argumentos en defensa do modelo inclusivo foron sinalados é necesario estabelecer que unha forma participativa de democracia como aquela que representa este modelo, coincidente coa democracia verde na necesidade de que as cidadás e cidadáns sexan activos na definición e control do principio de sostibilidade, non é neutral respecto ás dimensión do espazo político en que é chamada a se realizar. A política inclusiva esixe unha comunitarización que permita ou desenvolva un debate efectivo e non distorsionado. Devandita comunitarización non só facilitaría a comunicación entre os actores, facéndoa posíbel dende un punto de vista práctico e funcional, senón que tamén permitiría respectar a orientación consensual da deliberación. Se un asunto debe abordarse por unha asociación democrática, esta debe ser a asociación máis pequena que poda abordalo de xeito satisfactorio, porque as democracias máis pequenas ofrecen máis oportunidades á cidadanía de participar eficazmente nas decisións, ao lles proporcionar maior poder de decisión e influencia; agora ben, isto reduce á vez a dimensión do sistema político e minimiza o número e a calidade dos asuntos susceptíbeis de control cidadá, así como as oportunidades individuais de desenvolver as súas habilidades especializadas que son tamén habilidades necesarias para a solución racional de problemas colectivos (Przeworski, 1999; Weitbust, 2009). Do que se trata non é de dar forma a unha democracia pequena, senón de artellar politicamente e institucionalmente un conxunto de comunidades de decisión no ámbito dunha democracia que tamén inclúa outras formas de institucionalización. Non hai que esquecer 
os perigos asociados a unha comunitarización radical como a proposta dalgúns modelos de sostibilidade (cf. Paredes, 2010; Lanza, 2012; Cochrane, 2014). A especialización social e a complexidade funcional invalidan todas as formas de democracia primaria (cf. Cochrane, 2000). A democracia inclusiva verde constitúese, antes ben, como unha rede de comunidades discursivas vinculadas entre si e conectadas simultaneamente con institucións representativas rexidas por principios deliberativos, necesarias para a coordinación política e funcional.

Os límites da comunitarización discursiva e da institucionalización de marcos deliberativos proxectados na esfera pública e informal refírense, sobre todo, á racionalidade funcional do sistema político e á necesidade de artellar as relacións entres as devanditas comunidades, os órganos políticos representativos e o poder administrativo. Porque a representación política non desaparece nunha democracia inclusiva verde, algo en última instancia impensábel dada a configuración social e a imposibilidade de que se delibere todo en todas partes, senón que cumpre unha función esencial de coordinación e equilibrio (cf. Arias Maldonado, 2008). Unha democracia deliberativa sen representación política non é, simplemente, viábel. Por conseguinte, é mellor formalizar a deliberación nunha base representativa (Saward, 2000:72). Esta representación non se reduce ás institucións representativas xa existentes, modificadas mediante a súa suxeición aos criterios deliberativos. A devandita suxeición é, naturalmente, necesaria pero non é suficiente. Se falamos de satisfacer os criterios da deliberación e dunha representación plena, hai que introducir modificacións substanciais no actual sistema representativo (cf. Gargarella, 2001; Przeworski, 2010). Así, é preciso ir alén e crear mecanismos representativos que faciliten a cohesión dun sistema político pluralista e fragmentado en diferentes niveis de decisión.

A representación política nunha democracia inclusiva verde é tan diversa como os contextos en que é chamada a se desenvolver. Esta representación, na medida en que ocorre nun marco institucional rexido por principios discursivos, é unha representación deliberativa, orientada á obtención dun consenso entre os diferentes actores, á vez procedentes de comunidades ou órganos de deliberación, como nun sistema de vasos comunicantes. Representación deliberativa é suxeición do proceso político aos principios dun debate razoado e á decisión consensual cando esta sexa posíbel (cf. Maiz, 2006). Agora ben, cal é aquí a relación que mantén representante e representado? Anne Philips (1995) distingue unha política de ideas, baseada na presunción de concordancia entre representantes e representados e é principalmente unha representación de opinións e crenzas; e unha política da 
presenza, chamada a operar aí onde a primeira se revela ineficaz ou exclusiva. $\mathrm{Na}$ democracia inclusiva verde, a política de ideas operará alí onde representantes de comunidades discursivas, ou foros creados ad hoc, teñan que deliberar á vez con outros representantes, a efectos de coordinación ou negociación. Unha política da presenza será necesaria nos casos en que os axentes afectados pola decisión non podan representarse a si mesmos, por exemplo, as vindeiras xeracións, o mundo natural ou as persoas nonhumanas.

Sen embargo, é posíbel facer unha outra distinción para esclarecer a natureza da representación deliberativa. Ankersmit (1996) diferenza entre a concepción mimética e a concepción estética da representación. Segundo a primeira, os representantes deben reflectir ao representado tan fielmente como sexa posíbel; de acordo coa segunda, a diferenza entre representante e representado, a súa ausencia de identidade, é tan inevitábel coma desexábel. A democracia inclusiva verde contén, en correspondencia coa súa diversidade formal, as dúas formas de representación; é, de feito, unha combinación de ambas as dúas. Por unha banda, a representación que emana das comunidades e foros que alcanzaron unha decisión, que ten que se comunicar a outros órganos ou institucións de cara a súa coordinación ou negociación, responde de forma forzada ao modelo de representación mimética, servindo así aos fins da propia política deliberativa; a decisión lexitimada polo procedemento deliberativo é transferida sen mudanza ningunha a outro nivel ou esfera institucional. Xunto a este forma de representación coexiste a concepción estética, que é típica dos órganos parlamentares e tamén nas propias comunidades discursivas cuxa composición non é exhaustiva respecto do ámbito nela encarnado politicamente. Promóvese a diversidade do debate, e en consecuencia a vitalidade e pluralismo da esfera pública. Pensemos, por exemplo, nos foros deliberativos creados a través de sorteos que xurdiran nos últimos anos (cf. Franco Barrera, 2015).

\section{A modo de conclusión}

Non hai dúbida de que o resto das nosas vidas estará marcado pola mudanza climática e as súas consecuencias. Non existirá ningunha esfera da vida que non se vexa afectada en maior ou menor grao por este fenómeno global, dende a saúde até o ocio, pasando polo traballo e polas formas de organización social. As consecuencias das alteracións climáticas, e das políticas públicas que son empregadas para retardalo ou reducilo, implicarán 
unha gran mudanza na nosa sociedade e nas condicións de vida da maioría. O que está en xogo é o significado do devandito cambio.

É obvio que, de non tomar ningunha acción real para reducir as emisións, estaremos no camiño cara a extinción; pero, iso non acontecerá. A zona de perigo realmente realista é unha combinación de moita descarbonización, que ocorre demasiado tarde, no contexto dun endurecemento das desigualdades; en suma, un eco-apartheid. Canto menos fagamos para reducir as emisións a través dun extenso programa de intervención económica equitativa máis cerca estaremos dese escenario. Sen embargo, para evitar o peor dos escenarios catastróficos no clima, vaise necesitar unha inmediata e sostida mobilización global sen precedentes na historia.

Agora ben, a pesares das súas eivas, o Acordo de Paris supón un antes e un despois na resposta global ante as alteracións climáticas. A fase de diagnóstico está superada; non só unha gran maioría dos científicos que estudan o clima coinciden no feito de que a acción humana é a causa esencial da mudanza climática que observamos na actualidade. Arestora os gobernos teñen asumido un compromiso firme fronte ao mesmo. É por tanto necesario pasar á acción. As institucións, o tecido produtivo e todos os axentes sociais públicos e privados, incluíndo toda a cidadanía, debe agora tomar un papel activo e coordinado para evitar o anteriormente mencionado eco-apartheid.

Noutras palabras, a mudanza climática moldeará a forma na cal coñecemos a democracia. Non obstante, a democracia tamén pode moldear ás alteracións climáticas e os seus efectos sobre as sociedades; pero para alcanzar algún tipo de eficacia é necesario traballar nunha combinación das distintas formas democráticas, xa sexan deliberativas ou directas, xunto a unha concepción máis ampla da democracia representativa. En suma, recuperar o mellor da tradición libertaria do ecoloxismo político pero coa consciencia de moitos dos seus límites; tales como: o regulamento de comportamentos non-ecolóxicos, a falla de coordinación efectiva a escala superior do local ou a súa negativa de interpelar ás institucións.

O modelo inclusivo de democracia persegue ese camiño. Isto é, a súa adopción serve para a construción dunha democracia verde que ten como fins a democratización da democracia e a sostibilidade; distinguíbel, así, doutros xeitos que só procuran un dos dous principios pero non o seu vencello. O vínculo resulta da concepción aberta deste último, e a adopción do modelo inclusivo serve aos propósitos da democratización en relación á sostibilidade; a conformación discursiva deste último principio e o seu posterior control e redefinición pública ocorren durante os procedementos inclusivos, formais e informais, que constitúen o marco institucional de 
decisión nunha democracia verde. A deliberación pública é, por tanto, o medio para definir a sostibilidade. A definición institucional da democracia verde corresponde ás directrices fornecidas pola redefinición verde das institucións liberais.

O carácter normativo do principio de sostibilidade implica a súa aceptación como un ideal social regulamentar cuxa definición corresponde aos diferentes contextos sociais do discurso, nun proceso continuo de discusión, avaliación, aplicación e revisión da política de sostibilidade nos seus diferentes niveis, tanto xerais como parciais. Como a propia democracia, a sostibilidade nunca será concluída; como un proceso de aprendizaxe social, é permanentemente sometida a escrutinio e debate público. A flexibilidade que distingue á democracia inclusiva é especialmente indicada para a articulación dun debate que envolve a sectores sociais e en que diferentes tipos de discursos converxen.

Para tratar coas mudanzas duras que están por vir, debemos recoñecer urxentemente o carácter esencialmente indeterminado e aberto da sostibilidade, democratizando a súa definición estabelecendo os procedementos e principios necesarios para a súa determinación e xestión colectiva. O recoñecemento da calidade política da sostibilidade e a consecuente necesidade de artellar prescriptiva e institucionalmente a súa definición e control presupón un rexeitamento de toda determinación pre-política que, pola contra, poda comprometer unha abordaxe liberal baseada na xestión tecnocrática da sostibilidade. En contrapartida, a concepción aberta da sostibilidade e a orientación inclusiva da democracia verde ten un acento liberal indubidábel, pero que presupón necesariamente unha mudanza obrigatoria con relación á concepción liberal da democracia. A democracia verde, entón, sinala unha nova orde democrática baseada nunha combinación do marco deliberativo e de mecanismos representativos corrixidos de acordo co contexto institucional en que están inseridos e a función que os mesmos cumpren.

Unha participación maioritaria, e máis inclusiva, como a defendida nestas liñas, ademais de lexitimar as políticas públicas permitiría xerar políticas máis informadas, mellor comprendidas e máis xustas, e aumentar a confianza nas institucións. A participación social contra as alteracións climáticas é fundamental, dado que é a sociedade no seu conxunto o actor último das mudanzas requiridas. Ademais, existen bastante probas que sinalan que instaurar estruturas de poder máis democráticas non só garantirá unha resposta máis xusta, senón tamén máis resiliente aos impactos das alteracións climáticas (O’Brien, Hayward \& Berkes, 2009). Aquelas comunidades que maximizan a participación e a inclusión teñen moitas máis probabilidades 
de xerar a flexibilidade, creatividade e fortaleza colectiva necesaria para afrontar as numerosas e rápidas mudanzas e tensións que están por vir.

É necesario, entón, reivindicar a nosa capacidade para incidir no futuro, sendo conscientes de que a crise climática deixou exposta de forma moi evidente as grandes crises do capitalismo. Por tanto, esta é unha ocasión crítica para mudar de rumbo xa sexa para impedir unha crise maior ou para responder mellor aos seus impactos. Nada de isto garante un futuro mellor, pero deixa aberta as posibilidades para o mesmo.

\section{Bibliografía}

Ankersmit, Frank Rudolf (1996), Aesthetic Politics. Political Philosophy Beyond Fact and Value, Stanford, Stanford University Press.

Arias Maldonado, Manuel (2008), Sueño y mentira del ecologismo: naturaleza, sociedad, democracia, Madrid, Siglo XXI.

Chancel, Lucas E Piketty, Thomas (2015), Carbon and Inequality: From Kyoto to Paris. Trends in the global inequality of carbon emissions (1998-2013) \& prospects for an equitable adaptation fund, Paris, Ecole D'Economie de Paris.

Cochrane, Regina (2000), "Left-libertarian ecopolitics and the contradictions of naturalistic ethics: The Teology Issue In Social Ecology", en Democracy and Nature, vol. 6, n 2, páxs. 161-186.

Cochrane, Regina (2014), "Climate Change, Buen Vivir, and the Dialectic of Enlightenment: Toward a Feminist Critical Philosophy of Climate Justice", en Hypatia, vol. 29, no 3, páxs. 576-598.

Dobson, Andrew (1993), "Critical Theory and Green Politics", en Dobson \& Lucardie (ediciación a cargo de), The Politics of Nature, London, Routledge. Páxs. 190-209.

Dobson, Andrew (1996), "Democratising Green Theory: Preconditions and Principles”, en Doherty \& Gets (edición a cargo de), Democracy and Green Political Thought, London, Routledge. Páxs. 132-148.

Dobson, Andrew (1997), Pensamiento político verde. Una nueva ideología para el siglo XXI, Barcelona, Paidós.

Donaldson, Sue E Kymlicka, Will (2011), Zoopolis. A Political Theory of Animal Rights, Oxford, Oxford University Press.

Dryzek, John (1990), Discursive Democracy, Cambridge, Cambridge University Press.

Dryzek, John (1994), "Ecology and Discursive Democracy: Beyond Liberal Democracy and the Administrative State", en Goodin (edición a cargo 
de), The Politics of Environment, Aldershot, Edward Elgar. Páxs. 394418.

Dryzek, John (1995), "Political and Ecological Communication", en Environmental Politics, vol. 4, no 4, Inverno, páxs. 13-30.

Dryzek, John (1996), Democracy in Capitalism Times: Ideals, Limits, and Struggles, New York, Oxford University Press.

Dryzek, John (2006), Deliberative Global Politics: Discourse and Democracy in a Divided World, Cambridge, Polity.

Eckersley, Robyn (2000), "Deliberative Democracy, Ecological Representation and Risk: Towards Democracy of the Affected", en Saward (edición a cargo de), Democratic Innovation. Deliberation, Representation and Association, London, Routledge. Páxs. 117-132.

Escrivà, Andreu (2017), Encara no és tard: Claus per entendre i aturar el canvi climatic, Alzira, Edicions Bromera.

Fotopoulos, Takis (1997), Towards An Inclusive Democracy. The Crisis of the Growth Economy and the Need for a New Liberatory Project, London, Cassel Continium.

Franco Barrera, Alberto José (2013), "La filosofía crítica como herramienta para un concepto de sostenibilidad normativo", en Astrolabio. Revista internacional de filosofía, $\mathrm{n}^{\circ} 15$, páxs. 122-130.

Franco Barrera, Alberto José (2015), "Crise contra a representação política", en Pensando as crises (séculos XX-XXI). Desde a cultura galaicominhota, Atas do XI Simpósio Internacional Galaico-Minhoto de Filosofía. Páxs. 33-48.

Gargarella, Roberto (2001), "Representación plena, deliberación e imparcialidad", en Elster (edición a cargo de), La democracia deliberativa, Barcelona, Gedisa. Páxs. 323-346.

Goodin, Robert E. (1996), "Enfranchising the Earth, and its Alternative", en Political Studies, XLIV, no 5, páxs. 835-849.

Herring, Stephanie C.; Christidis, Nikolaos; Hoell, Andrew; Kossin, James P.; Schreck Iii, Carl J; E, Stott, Peter A. (edición a cargo de) (2018), "Explaining Extreme Events of 2016 from a Climate Perspective", en Bulletin of the American Meteorological Society, vol. 99, $\mathrm{n}^{\circ}$ 1. [Recurso Electrónico][Última revisión o 02/02/18]

Holland, Alan (1998), "Sustainability: Should We Start Form Here?”, en Dobson (edición a cargo de), Fairness and Futurity. Essays on Environmental Sustainability and Theories of Distributive Justice, Oxford, Oxford University Press. Páxs. 46-68.

IPCC (2014), Climate Change 2014: Synthesis Report Contribution of Working Groups I, II and III to the Fitht Assestment Report of the 
Intergovernamental Panel on Climate Change, [R.K. Pachauri e L.A. Meyer (edición a cargo de)], Geneva. [Recurso Electrónico]

Johnson, James (2001), “Argumentos en favor de la deliberación. Algunas consideraciones escépticas”, en Elster (edición a cargo de), La democracia deliberativa. Barcelona, Gedisa. Páxs. 207-234.

Klein, Naomi (2015), Esto lo cambia todo. El capitalismo contra el clima, Barcelona, Paidós.

Lanza, Martha (2010), “Buen Vivir: An Introduction from a Women's Rights Perspective In Bolivia", en Feminist Perspectives Towards Transforming Economic Power: Topic 2, Buen Vivir, Toronto, Association for Women's Rights in Development (AWID). [Recurso Electrónico][Última revisión o 20/12/17]

Maiz, Ramón (2006), "Deliberación e inclusión en la democracia republicana”, en REIS, ${ }^{\circ} 113$, páxs. 11-47.

Mouffe, Chantal (2012), La paradoja democrática: el peligro del consenso en la política contemporánea, Barcelona, Gedisa.

O’brien, Karen; Hayward, Bronwyn; e, Berkes, Fikret (2009), "Rethinking Social Contracts: Building Resilience in a Changing Climate", en Eco$\operatorname{logy}$ and Society, vol. 14, $\mathrm{n}^{\circ}$ 2. [Recurso Electrónico][Última revisión o 18/12/17] https://doi.org/10.5751/ES-03027-140212

Paredes, Julieta (2010), Hilando fino desde el feminismo comunitario, La Paz, Comunidad Mujeres Creando Comunidad y CEDEC. [Recurso Electrónico][Última revisión o 20/12/17]

Philips, Anne (1995), The Politics of Presence, New York, Oxford University Press.

Przeworski, Adam (1999), Democracy, Accountability, and Representation, Cambridge, Cambridge University Press. https://doi.org/10.1017/ CBO9781139175104

Przeworski, Adam (2010), Qué esperar de la democracia: límites y posibilidades de gobierno, Buenos Aires, Siglo XXI.

Puleo, Alicia (2011), Ecofeminismo para otro mundo posible, Madrid, Cátedra.

Saward, Michael (2000), "Less Than Meets the Eyes: Democratic Legitimacy and Deliberation Theory", en Saward (edición a cargo de), Democratic Innovation. Deliberation, Representation and Association, London, Routledge. Páxs. 66-77.

Sekulova, Filka E Bergh, Jeroen C.J.M. van der (2013), "Income, Climate and Happiness: An empirical study for Barcelona", en Global environmental change, vol. 3-5, páxs. 1467-1475. 
Swyngedouw, Erik (2010), “Apocalypse Forever? Post-political populism and the spectre of climate change", en Theory, Culture \& Society, vol. 27(2-3), páxs. 213-232.

Torgerson, Douglas (1999), "Images of Place in Green Politics: The Cultural Mirror of Indigenous Traditions", en Fischer \& Hacer (edición a cargo de), Living with Nature. Environmental Politics as Cultural Discourse, Oxford, Oxford University Press. Páxs. 186-203.

Valencia Sáiz, Ángel (2000), "Teoría política verde: balance de una disciplina emergente", en Revista Española de Ciencia Política, n 3 , páxs. 181-194.

Valencia Sáiz, Ángel (2004), “Teoría política y ecologismo: Algunas claves de la actual teoría política verde”, en Valencia Sáiz y Fernández-Llébrez (edición a cargo de), La Teoría Política frente a los problemas del siglo XXI, Granada, Universidad de Granada. Páxs. 181-200.

Weale, Albert (1993), "The Limits of Ecocentrism", en Environmental Politics, vol. 2, $\mathrm{n}^{\circ}$ 2, páxs. 341-344.

Whitworth, Andrew (2001), "Ethics and Reality Holism and the Democratic State: Are They in Conflict?", en Environmental Politics, nº 2, páxs. 125-136.

Young, Iris M. (2001), “Teoría Política: una visión general”, en Goodin y Klingemann (edición a cargo de), Nuevo Manual de Ciencia Política. Vol. II, Tres Cantos, Ediciones Istmo. Páxs. 693-726. 